\title{
SEM Evidence of Acidithiobacillus ferrooxidans (Af) Attachment to Sulfide Refractory Ore Surface.
}

de Lira P.*, Córdoba. L.**, Orrantia E.*, Flores S.*, Makita, M.****, Uribe A.***, Solís F.**

*Centro de Investigación en Materiales Avanzados, S. C. Miguel de Cervantes \#120, Chihuahua, Chih., 31109 México.

**Facultad de Medicina, Universidad Autónoma de Chihuahua. P. O. Box 1090, Chihuahua, Chih., 31000 México.

***Centro de Investigación y de Estudios Avanzados del IPN. Carretera Saltillo-Mty Km 13 Ramos Arizpe, Coah., 25900 México

****Instituto Tecnológico de Chihuahua II. Av. de la Industria \#11101. Chihuahua, Chih., 31109

México.

e-mail: patricia.delira@cimav.edu.mx

Bioleaching implies the use of bacteria for either the extraction or purification of minerals, and currently, is considered as one of the modern technologies which have one of the most solid application perspectives[1]. An isolated microorganisms for such task is Acidithiobacillus ferrooxidans (Af), which has attracted a great interest for knowing its bioleaching mechanism. It is known that this bacteria obtains its energy from the oxidation of ferrous ions and from inorganic sulfur[2], suggesting that for this microorganism it is required the interaction bacteriamineral[3]. During this interaction, polysaccharides are synthesized as an evidence of sulfur oxidation, with the consequent mineral dissolution. In the present research, the techniques of scanning electron microscopy (SEM;) and energy dispersive analysis by X-rays EDAX) were used. From these it could be suggested that the mentioned interaction have been taken in specific zones of the mineral.

Materials

Strain T18 of $A f$, adapted to $1,800 \mathrm{ppm}$ of As, was used as culture medium 9K; crystals of sulfide (pyrite) were used as mineral; a standard methodology for bacteria fixation for its observation by scanning electron microscopy (Jeol Model JSM5800LV) was implemented. Two mineral cultures were prepared for present study, both under the same experimental parameters, one of the cultures without the strain of the $A f$ (control).

Results.

SEM analysis of both samples indicated a significant difference between the surface of the control sample and the one of the sample that contained the $A f$. In the first, the surface(Fig 1) apparently smooth and uniform did not present the presence of polysaccharides, while the second, besides showing the presence of $A f$, it generated polysaccharides and a rugged and irregular surface (Fig.2). The chemical composition of some interest zones, were determined through EDAX, obtaining organic compositions in the mineral with $A f$, and inorganic compositions in the control sample.

Conclusions.

The techniques of SEM and EDAX showed that $A f$ acts in a selective way in the minerals surface, showing after the first 12 hours of contact between bacteria and mineral the presence of 
polysaccharides. On the other hand, the control sample showed us insignificant changes in the surface, which allows us to suggest that $A f$ adheres in zones highly concentrated with sulfur.

\section{References.}

[1] Lynn NS. 1997. Journal of Minerals, Metals and Materials 49 (4):24-26

[2] Fowler T.A., and F.K. Crundwell. 1998. Appl. Environ Microbiol. 64:3570-3775.

[3] Sugio et al. 1990. Agric.Biol. Chem, 54:2293-3398.
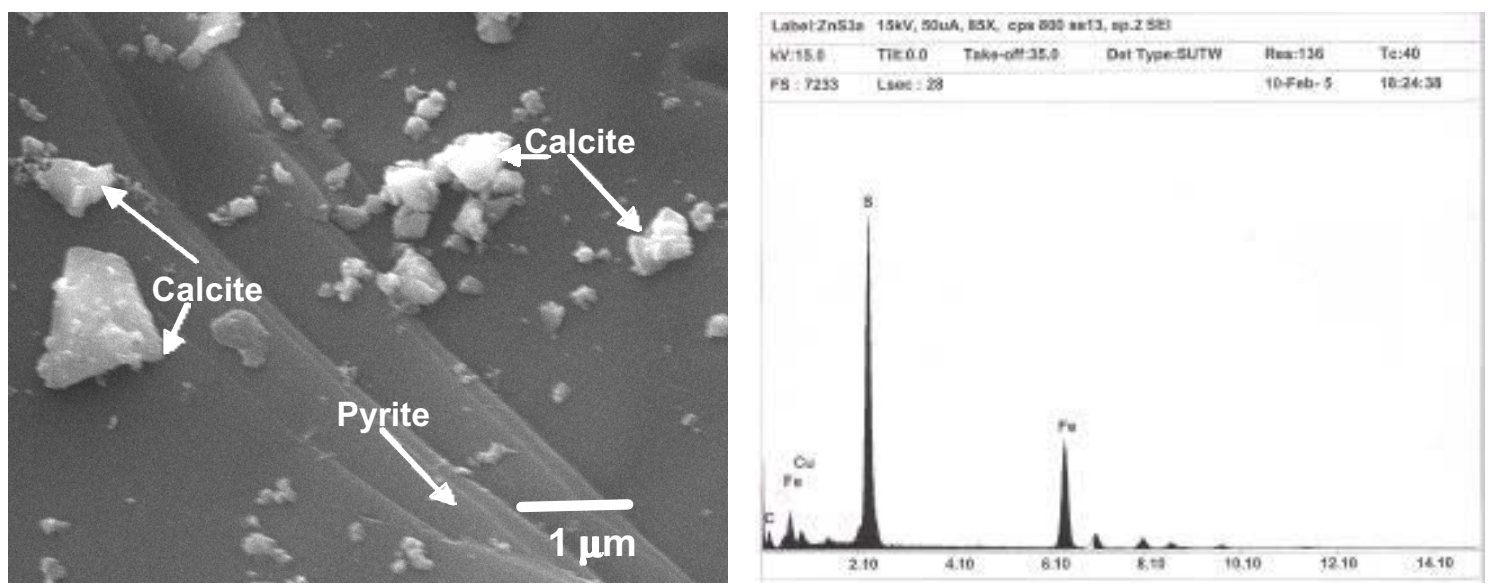

FIG. 1.- SEM and EDAX of surface of the control sample
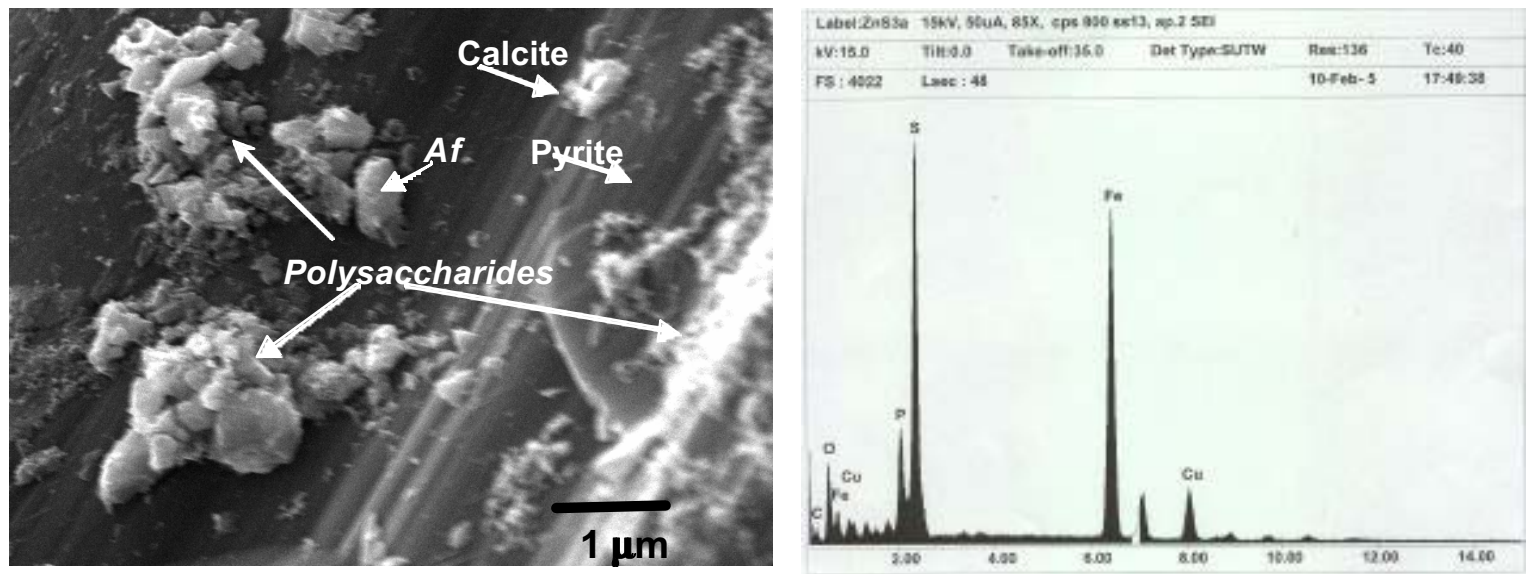

FIG: 2.- SEM and EDAX of surface of the sample that contained the $A f$. 